\title{
ON THE RELATIONSHIP BETWEEN THE PROMOTION OF ENVIRONMENTAL SUSTAINABILITY AND THE INCREASE OF TERRITORIAL COMPETITIVENESS: THE ITALIAN CASE
}

\author{
R. PAPA ${ }^{1}$, C. GARGIULO ${ }^{1}$, L. RUSSO $^{1} \& \mathrm{~S}_{\text {. FRANCO }}^{2}$ \\ ${ }^{1}$ University of Naples "Federico II", Italy. \\ ${ }^{2}$ LUISS Guido Carli University, Rome, Italy.
}

\begin{abstract}
The consequences of climate change urges researchers to investigate the issues of environmental sustainability, and the definition of policies for reducing greenhouse gas emissions (GHG) has become more urgent. In this context, urban areas play a significant role since here, economic, productive and social activities are concentrated and, therefore, the majority of the GHG emissions are produced. For these reasons, many cities worldwide are making big efforts to improve their level of environmental sustainability, but is this a worthy investment in terms of territorial competitiveness? In the era of globalization, indeed, countries, regions and cities cannot underestimate the competition against each other to attract firms, people and skills. Therefore, the aim of this paper is to identify the type of relationship between environmental sustainability and territorial competitiveness at the city level in order to verify whether or not it is possible to positively affect competitiveness by investing on green initiatives.

The study measures the level of environmental sustainability and competitiveness of 103 Italian capital cities by constructing two composite indicators and it compares the two performances using a statistical approach, showing that being green also means being more competitive and this positive relationship increases proportionally with the population. In other words, strategies designed to make a city more environmentally sustainable positively affect its level of competitiveness, and this correlation is stronger for bigger cities.
\end{abstract}

Keywords: composite indicators, environmental sustainability, Italian cities, territorial competitiveness.

\section{INTRODUCTION}

Since the 1990s, with the spread of the globalization phenomenon and the fast economic growth of emerging countries, territories have striven to create the best conditions in order to attract investments, talents and skills [1]; therefore, the issue of territorial competitiveness has become a central theme for urban planners and decision makers [2-6]. At the same time, the increasingly evident consequences of climate change urge researchers to investigate the issues of environmental sustainability, and the definition of "green" policies has become more urgent. However, despite a great number of environmental strategies that have been developed worldwide, only some countries have achieved ambitious sustainable targets while others still have to find the correct direction [7]. The dissimilarities in environmental performances amongst countries fuel the debate on the causes of environmental gains and focus the attention on the relationship between environmental policies and economic growth [8-10]. 
Several studies have demonstrated a positive association between environmental performance and national competitiveness contesting the thesis of the trade-off between being green or being competitive [4, 10, 11]. Furthermore, with the 2014-2015 edition of the Global Competitiveness Report, a prestigious international institution such as the World Economic Forum (WEF) has been trying to integrate the concept of sustainability into its competitive work in order to better explore this relationship. The interest for the topic, both from academia and institutional organizations, proves its relevance; nevertheless, the linkages between competitiveness and environmental sustainability has mainly been investigated on the national scale, while further consideration should be given to local level. Cities, in fact, play a significant role in the challenge for environmental sustainability since the majority of the population lives here and, therefore, economical, productive and social activities are concentrated; these activities require the consumption of large amounts of resources and produce high level of greenhouse gas emissions [12]. For these reasons, a successful environmental policy needs to be implemented at the urban level [13-16], and the potential relationship with territorial competitiveness should be evaluated on this scale. Moreover, the benchmarking at a national level does not properly capture the variation in competitiveness within a country, which seems to be significant, at least in the European Union [17].

This paper aims to better understand this relationship on an urban scale in order to measure how environmental sustainability strategies affect competitiveness. In other words, this work seeks to identify the type of connection existing between a city's environmental performance and its aptitude to attract investments, talents and firms. Any existing relationship can represent a useful support for policy makers in defining an appropriate structure of environmental policies on the city scale, contributing to a sustainable economic growth [9].

The analysis has been carried out on 103 Italian province capitals by developing an Index of City Environmental Sustainability (iCES), which allowed to assess the environmental performance of the capitals and compare it to their level of competitiveness, measured by the Index of City Competitiveness (iCC) constructed in previous works [18, 19] and herein improved.

The structure of the paper is as follows: in Section 2 we review the major scientific contributions to the debate on the trade-off between environmental sustainability and territorial competitiveness; Section 3 includes a review of the main composite indicators constructed for measuring both sustainability and urban competitiveness; in Section 4 we report the methodology used to develop both the iCES and that of Competitiveness and their application to the Italian capitals; in Section 5 we compare the cities' performance measured by the iCES with those measured by the iCC in order to point out the type of association that exists between environmental results and competitive strength, for each capital city; in Section 6 we provide some concluding remarks and possible further research.

\section{SCIENTIFIC FRAMEWORK}

In the first part of this Section we explore the conceptual definition of urban sustainability, and we then investigate the more specific concept of environmental sustainability. In the second part, we highlight the main scientific contributions describing the concept of territorial competitiveness.

\subsection{Defining environmental sustainability}

Environmental sustainability is part of the wider concept of sustainable development that has become popular since its first definition provided by the Brundtland Report in 1987. Despite 
a great number of interpretations that have been given to this concept, its definition remains vague $[10,15]$ mostly due to the heterogeneity of the actors involved [20, 21]. Nevertheless, by considering the great number of studies related to it, researchers seem to agree on two main ideas: sustainable development imposes a convergence between environmental, economical and social aspects - the so-called triple bottom line [22] - and it calls for a long-time equity between present and future generations [10, 14, 15, 23, 24]; in other words, a territory is sustainable when its economic and social growth respects the environment in a forwardlooking perspective.

It is a shared opinion that the three rings [20] should not be considered independently because of their significant interactions, so that a holistic approach, which gives the same priority to any of the three dimensions, better represents the concept of sustainable development because it does not underestimate the connections between the environment, economy and society $[10,20]$. However, the aim of this paper is to focus the attention on the environmental dimension in order to investigate its possible relationships with territorial competitiveness. Giving priority to the environmental pillar does not imply the assumption that the three rings are mutually autonomous and that the fuzzy boundaries that separate them have to be restored; rather the effort of this analysis is to identify whether or not the best performing territories in terms of environmental results also show a significant competitive strength.

As far as environmental sustainability is concerned, the attention goes on the physical structure that characterizes urban systems and the goal is to promote an efficient use of resources, as well as the increase of green areas and the reduction of pollution and traffic congestion [9, 10]. Environmental sustainability depends on the natural and built elements a city is made of and it can be measured considering air, soil and water quality as well as accessibility and open spaces [25].

These aspects have attracted much attention during the last 20 years because of the dramatic consequences of climate change and global resource depletion. Therefore, the environmental unsustainability of urban areas has called for a political commitment in order to address this challenge by developing efficient and effective strategies. Despite the great effort made worldwide, environmental policies are too often seen as no more than "command and control" mandates rather than integrated and broad plans [9, 23]; a multilevel approach is required in order to better enhance the level of environmental sustainability of our territories, taking account of the linkages with their competitive strength.

\subsection{Defining territorial competitiveness}

Since the 1990s, competitiveness has been considered crucial for the development of territories. In the era of globalization, when countries, regions and cities have to compete amongst each other in order to attract capitals, business and talents, the concept of competitiveness, which originally was just referred to firms within the economic disciplines, has broadened its field of action leading to a long standing controversy. Critics argued that competition amongst territories is theoretically inappropriate since countries cannot go out of business as firms do $[2,26]$; on the contrary, advocates such as Porter [27] and Camagni [1] sustained the meaningfulness of territorial competitiveness, pointing out the increasing importance of knowledge and innovation in the definition of competitiveness at a global level.

Many definitions of territorial competitiveness have emerged over the past three decades. Most of them reflect an approach mainly based on productivity: Camagni [1] argues that "territories compete with one another, both to attract direct foreign investment and in defining a 
productive role for themselves within the international division of labor, without any automatic assurance of such a role"; along a similar line of thought, the WEF, in The Global Competitiveness Report 2014-2015, defines competitiveness "as the set of institutions, policies, and factors that determine the level of productivity of a country" [28] and the ECB considers "a competitive economy [as] one in which institutional and macroeconomic conditions allow productive firms to thrive [thus supporting] the expansion of employment, investment and trade" [29].

A wider perspective is provided by Dijkstra et al. [27], who define regional competitiveness "as the ability to offer an attractive and sustainable environment for firms and residents to live and work", considering strategies for gaining a competitive advantage both productivity and people. This multidimensional approach is enjoying success and it seems to better describe the complexity of the competitiveness phenomenon.

\section{COMPOSITE INDICATORS}

Composite indicators are increasingly considered a useful support for policy makers for a number of reasons: they are able to illustrate complex multidimensional phenomenon with a relatively small amount of information; they easily allow to compare the performance of territories, over time, in a wide range of field, such as environment, economy, innovation, society, etc...[30, 31]; and, they are a great means of communication. Nevertheless, like everything has its pros and cons, composite indicators have also some disadvantages, mainly related to the arbitrary nature of data selection and to some methodological issues; indeed, although the procedure for constructing a composite index can be considered to be widely agreed (1. Theoretical framework; 2. Data selection; 3. Normalization; 4. Standardization; 5. Weighting and aggregation), there is much less consensus as to the methodology that should be used for each step.

In the following part, the major environmental sustainability and territorial competitiveness indexes are reviewed. In particular, we focused our attention on the indicators selected for the development of each index and on the method used for weighting and aggregating them. This information provides the basis for the construction of both iCES and iCC for the sample of Italian cities.

\subsection{Review of the major environmental sustainability indexes}

There are a great number of indexes for measuring the level of sustainability of territories, and several groups of researchers have reviewed and compared them [15, 31, 32], providing interesting findings. Partially based on their results, we have focused our analysis on those composite indicators that evaluate the environmental dimension of territorial sustainability - the Global Adaptation Index (GAI); the Ecological Footprint (EF); the Environmental Performance Index (EPI); the Environmental Vulnerability Index (EVI); the Ecosystem WellBeing Index (EWB); the Ecosistema Urbano (EU) - and we have compared the number and types of variables selected, the territorial unit of analysis and the methodology used to construct the indexes.

If we consider the process of data selection, although the number of variables is different for the six indexes, the variables can be attributed to the same categories, which correspond to the different types of natural resources, such as water, air, wind, sea, land, energy, forests and food: resource use appears to be critical for measuring the environmental performance of a territory. 
As far as the spatial unit of analysis is concerned, five composite indicators out of six have been created for assessing environmental sustainability among countries, while only one of them - the Ecosistema Urbano by Legambiente - compares cities. As previously mentioned, the importance of addressing sustainability at the city level is becoming increasingly urgent as urbanization is concentrating more and more people and activities in urban areas and, therefore, the need to investigate the issue of environmental sustainability at this territorial unit of reference is becoming crucial. Nevertheless, the lack of reliable and consistent data on this territorial scale is preventing the development of indexes that could support and guide local administrator's decisions.

With regards to the methods used to weight and aggregate the indicators, two weighting criteria and two types of aggregation can be identified: three indexes rely on equal weighting and use the summation (EF) or the arithmetic mean (GAI; EVI) of normalized individual indicators for the composite index construction; the other three indexes assign weights using participatory methods, i.e. based on the opinion of various stakeholders, or using a statistical model, such as principal component analysis (PCA), and aggregate the individual indicators using the arithmetic mean of weighted and normalized data. Moreover, the Environmental Performance Index and the Ecosistema Urbano use a proximity-to-target methodology as a final step for indicator construction. This methodology calculates each item's score on any given indicator based on its distance to an assigned target [33]. The results of this comparison have supported the development of the iCES.

\subsection{Review of the major competitiveness indexes}

As previously described in Section 2.2, several scholars and institutions have investigated the issue of territorial competitiveness, but the need to rank countries, regions or cities to benchmark their level of competitiveness and to identify which factors determine their success is relatively recent. The increasing number of indexes measuring the level of competitiveness, indeed, suggests how relevant the issue is in our globalized society. The most used territorial unit of analysis is the country, mainly because the concept of territorial competitiveness finds its academic roots in the debate on the competition among nations [2, 34]. Nevertheless, more recent studies analysed competitiveness at the regional and urban level because the national scale does not consider the differences within a country, which seem to be significant [17].

We have here reviewed four indexes - the World Competitiveness Index (WCI); the Global Competitiveness Index (GCI); the Regional Competitiveness Index (RCI); the CCI - which refer to three different territorial scales, i.e. the national, regional and urban scale.

One of the first attempts to classify nations by the degree of competitiveness is that of the International Institute for Management Development (IMD) business school, which developed the first WCI in 1989. The last release of the index (2016) ranks 62 countries using 256 indicators, divided into four dimensions: economic performance, government efficiency, business efficiency, infrastructures; the IMD uses two types of data - hard and survey data and it assigns two different weights to the indicators depending on the type of data. A similar approach is that of the GCI constructed by the WEF since 2003; this index measures the competitive level of more than 140 countries analysing 114 indicators grouped into 12 dimensions. The WEF gives different weights to each dimension depending on the level of development of the considered country. In 2010, based on the GCI methodology, the European Commission developed the first RCI, comparing the competitive performance of 268 European regions. A different analysis has been carried out by the Intelligence Unit of The 
Economist (EIU) to benchmark the competitiveness of 120 cities across the world at two different points in time: 2013 and 2025. The index measures the level of competitiveness using 32 indicators, both qualitative and quantitative, grouped into eight categories or dimensions. Differently from the previous studies, in which an equal weight has been given to the indicators for countries with the same level of development, the EIU gives different weights to each dimension, based on the opinion of experts. As far as the aggregation method is concerned, three out of four indexes calculate the final competitiveness score for each entity by using the mean of weighted and normalized individual indicators.

As for the review of the main environmental sustainability indexes, the analysis of the competitiveness index has provided useful and essential information for the construction of the iCC.

\section{DATA \& METHODS FOR THE DEVELOPMENT OF THE INDEXES}

Two composite indicators have been developed in order to investigate the relationship between territorial competitiveness and environmental sustainability on urban scale: the iCES and the iCC allowed to measure and compare the performance of 103 Italian cities in respect to these two aspects. Both composite indicators have been constructed following the same methodology, which is based on the scientific framework previously described and can be structured in these four steps [30, 33]: (1) Data selection; (2) Normalization; (3) Standardization; (4) Weighting and aggregation.

The selection of the indicators is based on the review of the studies carried out to define and measure both territorial competitiveness and environmental sustainability, and on the availability of reliable data at city level. A set of 10 indicators have been selected for the development of the iCES and a set of 19 indicators has been used for the construction of the iCC, Table 1. Data for each indicator has been collected at 2011/2012 for 103 Italian cities; the Italian Institute of Statistics (ISTAT) represented the main source of data. Data collection allowed the construction of two matrixes, one $103 \times 10$ and the other $103 \times 19$. Some raw data required an operation of normalization in order to make the data comparable across entities; e.g., the indicator energy intensity $(\mathrm{kWh} /)$ is expressed as the ratio between the total energy consumption and the annual average income so as to measure the "eco-efficiency or resource productivity of a society" [4], and the data natural gas consumption $\left(\mathrm{m}^{3}\right)$ was divided by the number of degree days to reflect similar weather conditions. Then, the data were standardized in order to make the different scales comparable, using the z-score method. Before proceeding with the aggregation of the individual scores, the correlation matrix has been analysed in order to avoid multicollinearity.

The method for weighting and aggregating the indicators into the two final indexes has been chosen based on the review of the composite indicators previously described in Section 3. All variables were given the same weight - equal weighting - implying that each individual indicator has the same importance; once variables weights were assigned, individual scores have been aggregated using the arithmetic mean of the standardized values, so as to construct the two final indexes.

\section{RESULTS}

The construction of the iCES and the iCC allowed measuring the level of environmental sustainability and territorial competitiveness of 103 Italian cities, providing interesting findings, both from a geographical and dimensional perspective. In Table 2 we have provided the best and worst 10 positions for both the iCES and iCC rankings and, for each city, we have reported 
Table 1: List of indicators for the iCES and the iCC.

\begin{tabular}{|c|c|}
\hline iCES & $\mathrm{iCC}$ \\
\hline 1 Energy intensity (2011) & 1 Firms (2011) \\
\hline 2 Natural Gas consumption (2011) & 2 Exports (2011) \\
\hline 3 Water consumption (2012) & 3 Income (2012) \\
\hline 4 Loss of water (2012) & 4 Graduated population (2011) \\
\hline 5 Access to drinking water (2012) & 5 Number of Patents (2011) \\
\hline 6 Recycling (2012) & 6 R\&D employment (2011) \\
\hline 7 Air pollution (PM10) (2012) & 7 Education Facilities (2012) \\
\hline 8 Density of green areas (2012) & 8 Cultural Facilities (2012) \\
\hline 9 Efficiency of public transportation (2012) & 9 Foreign residents (2011) \\
\hline \multirow{10}{*}{$\begin{array}{l}10 \text { Municipal use of renewable energy } \\
\text { (2012) }\end{array}$} & 10 Rate of young residents (2011) \\
\hline & 11 Rate of old residents (2011) \\
\hline & 12 High Tech network (2011) \\
\hline & 13 Rail network (2012) \\
\hline & 14 Road network (2012) \\
\hline & 15 Energy consumption for production (2012) \\
\hline & 16 Unemployment (2011) \\
\hline & 17 Brank branches (2011) \\
\hline & 18 Cultural attractiveness (2011) \\
\hline & 19 Commuting (2011) \\
\hline
\end{tabular}

the indication of the geographical position - North, South, or Centre - as well as the demographic dimension - big, medium and small size. The geographical subdivision is the same employed by ISTAT, while the distinction between big, medium and small cities is based on this criterion: big cities have more than 250.000 inhabitants; medium cities have a population between 20.000 and 250.000 inhabitants; small cities have less than 20.000 inhabitants.

The classification of Italian cities based on their level of competitiveness shows, from a dimensional point of view, that densely populated cities occupy the podium of the ranking (Milan, Florence, Bologna) while just medium and small size cities are in the bottom part of the list. Furthermore, from a geographical dimension, the North-South divide emerges significantly, with a leader North (Milan, Bologna, Padova, Bergamo) and a weaker South (Trapani, Crotone, Enna, Caltanissetta, Oristano).

Looking at the ranking that measures the level of environmental sustainability of Italian cities, similar geographical considerations come out: the greener Italian cities are concentrated in the central and northern part of the country, while South Italian cities perform relatively poorly. Nevertheless, from a dimensional perspective, the iCES ranking shows same differences compared to the iCC one: the most sustainable Italian cities are either of medium or small size, while big cities are distributed only in the second, third and fourth quartile, with 3 big cities out of 12 in the last 10 positions (Roma, Palermo and Catania).

These considerations help to define a synthetic framework of the level of competitiveness and environmental sustainability within the Italian system and support the following analysis, 
which aims at comparing the two concepts in order to understand whether or not being more sustainable also means being more competitive.

The Pearson's correlation coefficient between the iCC and the iCES highlights a positive linear trend $-r=0.34-$ with a slope greater than zero. Nevertheless, stronger and more interesting results are provided if population size is considered. Table 3 shows that the correlation between environmental sustainability and competitiveness significantly increases with the population. Big cities, as shown in Fig. 1, reveal a strong positive correlation $(r=0.62)$, medium cities show a quite strong positive correlation $(r=0.48)$; on the contrary, for small cities the correlation does not identify any significant relationship $(\mathrm{r}=-0.04)$. In other words, the implementation of strategies aiming at improving the environmental sustainability of urban areas positively affect their level of competitiveness only if these areas are densely

Table 2: iCC and iCES by city, absolute rankings.

\begin{tabular}{|c|c|c|c|c|c|c|c|}
\hline $\mathrm{iCC}$ & City & Geography & Dimension & iCES & City & Geography & Dimension \\
\hline 1 & Milano & North & big & 1 & Pisa & Centre & medium \\
\hline 2 & Firenze & Centre & big & 2 & Verbania & North & small \\
\hline 3 & Bologna & North & big & 3 & Trento & North & medium \\
\hline 4 & Padova & North & medium & 4 & Biella & North & small \\
\hline 5 & Bergamo & North & medium & 5 & Forlì & North & medium \\
\hline 6 & Brescia & North & medium & 6 & Pesaro & Centre & medium \\
\hline 7 & Parma & North & medium & 7 & Siena & Centre & medium \\
\hline 8 & Treviso & North & medium & 8 & Pordenone & North & medium \\
\hline 9 & Pavia & North & medium & 9 & $\begin{array}{l}\text { Bolzano/ } \\
\text { Bozen }\end{array}$ & North & medium \\
\hline 10 & Mantova & North & small & 10 & Ancona & Centre & medium \\
\hline$\cdots$ & $\cdots$ & $\ldots$ & $\ldots$ & $\ldots$ & $\ldots$ & $\ldots$ & $\ldots$ \\
\hline 94 & Catania & South & big & 94 & $\begin{array}{l}\text { Vibo } \\
\text { Valentia }\end{array}$ & South & small \\
\hline 95 & Brindisi & South & medium & 95 & Catanzaro & South & medium \\
\hline 96 & Sassari & South & medium & 96 & Roma & Centre & big \\
\hline 97 & $\begin{array}{l}\text { Reggio } \\
\text { Calabria }\end{array}$ & South & medium & 97 & Frosinone & Centre & small \\
\hline 98 & Nuoro & South & small & 98 & Siracusa & South & medium \\
\hline 99 & Oristano & South & small & 99 & Palermo & South & big \\
\hline 100 & Caltanissetta & South & medium & 100 & $\begin{array}{l}\text { Reggio } \\
\text { Calabria }\end{array}$ & South & medium \\
\hline 101 & Enna & South & small & 101 & Benevento & South & medium \\
\hline 102 & Crotone & South & medium & 102 & Catania & South & big \\
\hline 103 & Trapani & South & medium & 103 & Imperia & North & small \\
\hline
\end{tabular}


Table 3: The correlations between iCC and iCES by city dimension.

\begin{tabular}{ll}
\hline city size & $\mathrm{r}$ \\
\hline big & 0.62 \\
medium & 0.48 \\
small & -0.04 \\
\hline
\end{tabular}

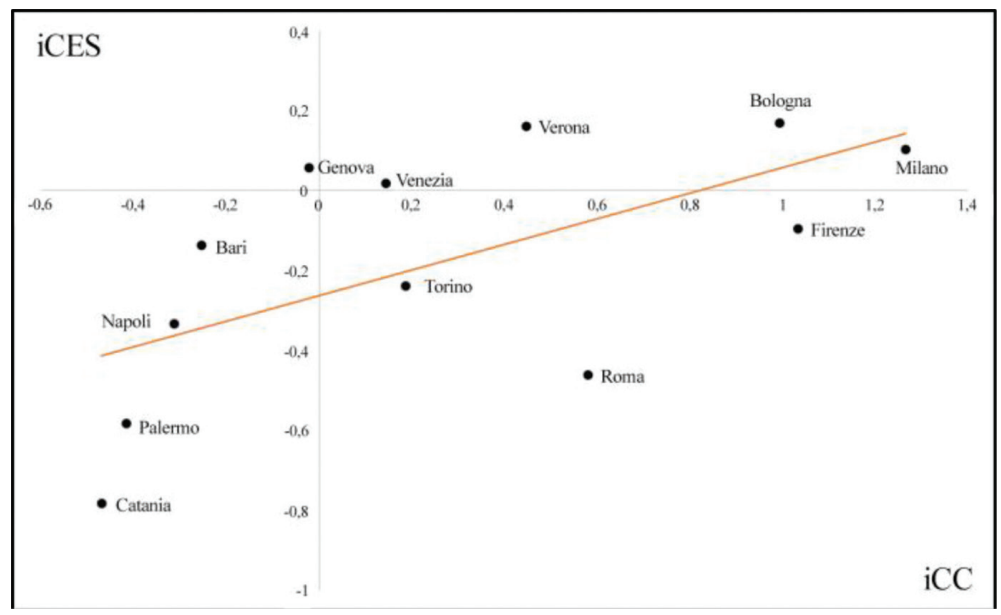

Figure 1: Relationship between environmental sustainability and territorial competitiveness for big cities.

populated. On the other hand, for smaller cities, the development of green initiatives does not have any impact on their level of competitiveness.

\section{CONCLUSIONS}

This analysis supports several preliminary but interesting policy implications.

First, the positive correlation revealed in Table 3 and Fig. 1 does not necessarily prove causation. Nevertheless, the finding that for big and medium size cities a greater quotient of environmental sustainability corresponds to a high level of competitiveness is itself interesting and useful from a decision-making perspective. Indeed, a significant positive correlation $(\mathrm{r}=0.62)$ between environmental sustainability and competitiveness at the city level for densely populated cities suggests that investing in "green" initiatives should be seen as a priority for local policy makers in order to create a competitive advantage. Our preliminary results indicate that, for bigger cities, the commitment towards a more sustainable urban development has immediate positive effects in terms of a city's attractiveness, despite the very high concentration of activities, goods and people; on the other hand, small cities, which are characterized by slower lifestyle and less density of functional relations and physical interactions, are places where the equilibrium between supply and demand is naturally more sustainable. The interest for the effective integration of economic, social and eco-friendly factors in the development of our cities reflects the ultimate evolution of urban culture, which considers sustainability a critical element of urban quality and, consequently, a determinant of cities' competitiveness. 
Second, the dramatic disparities in the level of competitiveness and sustainability among North and South Italian cities revealed by data stress the importance of differentiating strategies and interventions, as well as investments, in order to achieve better results both in terms of competitiveness and environmental sustainability. The gap between northern and southern territories can represent a point of weakness for the entire national system and, therefore, much greater strategic emphasis might be placed on implementing specific policies aimed at reducing it.

The preliminary results and conclusions presented here should be validated using time series data. Moreover, a possible agenda for further research should include the analysis of correlation between sustainable and competitive cities in other countries, to identify similarities and differences with the Italian context.

\section{REFERENCES}

[1] Camagni, R., On the concept of territorial competitiveness: sound or misleading? Urban Studies, 39(13), pp. 2395-2411, 2002. http://dx.doi.org/10.1080/0042098022000027022

[2] Krugman, P., Competitiveness: a dangerous obsession. Foreign Affairs-New York, 73, pp. 28-28, 1994. http://dx.doi.org/10.2307/20045917

[3] Krugman, P., Making sense of the competitiveness debate. Oxford Review of Economic Policy, 12(3), pp. 17-25, 1996. http://dx.doi.org/10.1093/oxrep/12.3.17

[4] Esty, D.C. \& Porter, M.E., National environmental performance: an empirical analysis of policy results and determinants. Environment and Development Economics, 10(4), pp. 391-434, 2005. http://dx.doi.org/10.1017/S1355770X05002275

[5] Rogerson, R.J., Quality of life and city competitiveness. Urban Studies, 36(5/6), p. 969, 1999. http://dx.doi.org/10.1080/0042098993303

[6] Turok, I., Cities, regions and competitiveness. Regional Studies, 38(9), pp. 1069-1083, 2004. http://dx.doi.org/10.1080/0034340042000292647

[7] Hu, R., Sustainability and competitiveness in Australian cities. Sustainability, 7(2), pp. 1840-1860, 2015. http://dx.doi.org/10.3390/su7021840

[8] Panayotou, T., Economic Growth and the Environment (No. 56). Center for International Development at Harvard University, 2000.

[9] Esty, D.C. \& Charnovitz, S., Environmental Sustainability and Competitiveness: Policy Imperative and Corporate Opportunity, Harvard Business School, 2011.

[10] Camagni, R., Capello, R. \& Nijkamp, P., Towards sustainable city policy: an economyenvironment technology nexus. Ecological Economics, 24(1), pp. 103-118, 1998. http://dx.doi.org/10.1016/S0921-8009(97)00032-3

[11] Esty, D.C., Levy, M.A., Srebotnjak, T., de Sherbinin, A., Kim, C.H. \& Anderson, B., Pilot 2006 Environmental Performance Index, Yale Center for Environmental Law \& Policy: New Haven, 2006.

[12] Un-Habitat, State of the World's Cities 2008-2009: Harmonious Cities, Earthscan, 2008. 
[13] Berardi, U., Sustainability assessment of urban communities through rating systems. Environment, Development and Sustainability, 15(6), pp. 1573-1591, 2013. http://dx.doi.org/10.1007/s10668-013-9462-0

[14] Egger, S., Determining a sustainable city model. Environmental Modelling \& Software, 21(9), pp. 1235-1246, 2006. http://dx.doi.org/10.1016/j.envsoft.2005.04.012

[15] Mori, K. \& Christodoulou, A., Review of sustainability indices and indicators: towards a new city sustainability index (CSI). Environmental Impact Assessment Review, 32(1), pp. 94-106, 2012. http://dx.doi.org/10.1016/j.eiar.2011.06.001

[16] Scipioni, A., Mazzi, A., Mason, M. \& Manzardo, A., The dashboard of sustainability to measure the local urban sustainable development: the case study of padua municipality. Ecological Indicators, 9(2), pp. 364-380, 2009. http://dx.doi.org/10.1016/j.ecolind.2008.05.002

[17] Annoni, P. \& Dijkstra, L., EU Regional Competitiveness Index, RCI 2013, European Commission. Joint Research Centre, 2013.

[18] Papa, R., Gargiulo, C., Franco, S. \& Russo, L., Measuring the effects of the 200809 financial crisis on the competitiveness of Italian provinces, Sustainable Recovery? Rebalancing, Growth, and the Space Economy, Regional Studies Association Winter Conference, pp. 193-199, 2014.

[19] Papa, R., Gargiulo, C., Franco, S. \& Russo, L., Urban smartness Vs urban competitiveness: a comparison of Italian cities rankings. Tema. Journal of Land Use, Mobility and Environment, Special Issue, pp. 771-782, 2014.

[20] Giddings, B., Hopwood, B. \& O'brien, G., Environment, economy and society: fitting them together into sustainable development. Sustainable Development, 10(4), pp. 187-196, 2002. http://dx.doi.org/10.1002/sd.199

[21] Salvati, L., Gargiulo Morelli, V., Weijnen, M., van Bueren, E., Wenzler, I. \& De Reuver, M., Towards intelligently - sustainable cities? Tema. Journal of Land Use, Mobility and Environment, 6(1), pp. 73-86, 2013.

[22] Pope, J., Annandale, D. \& Morrison-Saunders, A., Conceptualising sustainability assessment. Environmental Impact Assessment Review, 24(6), pp. 595-616, 2004. http://dx.doi.org/10.1016/j.eiar.2004.03.001

[23] Drexhage, J. \& Murphy, D., Sustainable Development: from Brundtland to Rio 2012, United Nations Headquarters, New York, pp. 9-13, 2010.

[24] Rogers, P.P., Jalal, K.F. \& Boyd, J.A., An Introduction to Sustainable Development, Earthscan, 2012.

[25] Aliberti, M., Measuring urban sustainability. Environmental Impact Assessment Review, 16, pp. 381-424, 1996. http://dx.doi.org/10.1016/S0195-9255(96)00083-2

[26] Lall, S., Competitiveness indices and developing countries: an economic evaluation of the global competitiveness report. World Development, 29(9), pp. 1501-1525, 2001. http://dx.doi.org/10.1016/S0305-750X(01)00051-1

[27] Dijkstra, L., Annoni, P. \& Kozovska, K., A new regional competitiveness index: theory, methods and findings. European Union Regional Policy Working Papers, 2, 2011.

[28] Schwab, K. \& Sala-i-Martin, X., The global competitiveness report 2014-2015, World Economic Forum: Geneva, 2014. 
306 Urban Regeneration and Sustainability

[29] Di Mauro, F. \& Ronchi, M., Assessing European competitiveness: the contribution of CompNet research, European Central Bank, 2015.

[30] Joint Research Centre-European Commission, Handbook on Constructing Composite Indicators, OECD publishing, 2008.

[31] Singh, R.K., Murty, H.R., Gupta, S.K. \& Dikshit, A.K., An overview of sustainability assessment methodologies. Ecological Indicators, 9(2), pp. 189-212, 2009. http://dx.doi.org/10.1016/j.ecolind.2008.05.011

[32] Böhringer, C. \& Jochem, P.E., Measuring the immeasurable-a survey of sustainability indices. Ecological Economics, 63(1), pp. 1-8, 2007. http://dx.doi.org/10.1016/j.ecolecon.2007.03.008

[33] Hsu, A., Johnson, L.A. \& Lloyd, A., Measuring Progress: A Practical Guide From the Developers of the Environmental Performance Index (EPI), Yale Center for Environmental Law \& Policy: New Haven, 2013.

[34] Porter, M.E., The competitive advantage of notions. Harvard Business Review, 68(2), pp. 73-93, 1990. 